\title{
Analisa Tidak Linier Mekanisme Keruntuhan Jembatan Busur Rangka Baja (A-Half Through Arch)
}

\author{
Abdul Rochim ${ }^{1, *}$, Bambang Piscesa ${ }^{1}$, Data Iranata ${ }^{1}$, Navir Afif Refani ${ }^{2}$ \\ ${ }^{1}$ Departemen Teknik Sipil, Institut Teknologi Sepuluh Nopember, Surabaya \\ ${ }^{2}$ Departemen Teknik Infrastruktur Sipil, Institut Teknologi Sepuluh Nopember, Surabaya \\ Koresponden*, Email: abdul.rochim.civeng@gmail.com
}

\begin{tabular}{|c|c|}
\hline Info Artikel & Abstract \\
\hline Diajukan 31 Januari 2019 & The collapses of steel truss bridges can be caused by some factors such as vehicle overloads, \\
\hline Diperbaiki 4 Februari 2019 & material deterioration (corrosion, fatique), and unexpected tsunami and/or earthquake loads. \\
\hline Disetujui 6 Februari 2019 & $\begin{array}{l}\text { However, in this paper, the study is limited only to the failure of a-half through arch bridge } \\
\text { due to earthquake loads. The bridge has a } 100 \mathrm{~m} \text { long span and is designed using the response } \\
\text { spectrum of Surabaya city, East Java, Indonesia. Static nonlinear push-over analysis is used } \\
\text { to investigate the performance and the collapse mechanism of the bridge. The bridge was } \\
\text { designed based on SNI 1725-2016 and SNI 2833-2016. From the analysis, the failure of the } \\
\text { structural elements occurred in the arch members located somewhere near the end portal. The }\end{array}$ \\
\hline $\begin{array}{l}\text { Keywords: collapses, pushover, a-half } \\
\text { through arch, performance }\end{array}$ & $\begin{array}{l}\text { performance level of the bridge determined using the Capacity Spectrum Method is at the } \\
\text { Immediate Occupancy (IO) level. }\end{array}$ \\
\hline
\end{tabular}

\begin{abstract}
Abstrak
Keruntuhan jembatan bisa disebabkan beberapa faktor seperti beban berlebih, fatik, korosi, gempa bumi dan/atau tsunami. Namun, dalam artikel ini, penelitian dibatasi hanya pada kegagalan jembatan busur dengan tipe a-half through arch bridge yang diakibatkan oleh beban gempa. Jembatan yang ditinjau memiliki bentang $100 \mathrm{~m}$ dan didesain sesuai dengan zona gempa kota Surabaya, Jawa Timur-Indonesia. Jembatan didesain dengan menggunakan SNI 1725-2016 dan SNI 2833-2016. Analisa beban dorong tidak linear digunakan untuk mengetahui kinerja dan mekanisme keruntuhan struktur jembatan. Berdasarkan hasil studi menunjukkan bahwa kegagalan elemen struktur jembatan terjadi pada elemen busur dekat portal akhir. Level kinerja struktur jembatan ditentukan dengan Metode Kapasitas Spektrum dan termasuk dalam level Immediate Occupancy (IO).
\end{abstract}

Kata kunci: keruntuhan, pushover, a-half through arch, kinerja

\section{Pendahuluan}

Indonesia adalah negara berkembang yang sedang melakukan pembangunan infrastruktur di seluruh wilayahnya. Salah satu pembangunan infrastruktur yang telah banyak dilakukan adalah konstruksi jembatan rangka baja. Dari beberapa jembatan yang telah dibangun tersebut ada yang telah melebihi batas umurnya dan perlu dilakukan investigasi untuk mengetahui kondisi jembatan. Kerusakan jembatan rangka baja disebabkan oleh kendaraan dengan beban berlebih dan kurangnya pemeliharaan jembatan [1]. Dalam tahun 2018, terdapat dua kasus jembatan rangka baja mengalami keruntuhan. Salah satunya adalah jembatan Ponulele yang runtuh saat terjadi gempa dan tsunami di Palu dan Donggala, Sulawesi Tengah pada 28 September 2018 [2]. Magnitude gempa yang terjadi diperkirakan sebesar 7.4 Richter dan menyebabkan terjadinya gelombang tsunami yang menerjang jembatan Ponulele tersebut. Sebelumnya, kegagalan struktur rangka baja lainnya juga terjadi di perbatasan Tuban-Lamongan, Jawa Timur pada 17 April 2018 dimana perkiraan penyebab dari runtuhnya jembatan adalah akibat beban overloading [3].

Kegagalan getas elemen struktur yang sering disebabkan oleh pelebaran retak akibat fracture pada umumnya sangat sulit untuk diprediksi. Elemen-elemen tersebut mungkin sudah mengalami fatik terlebih dahulu akibat adanya pengulangan beban siklik yang lama diaplikasikan pada struktur tersebut (jembatan lama). Lebar retak yang kecil pada elemen baja dapat menyebabkan elemen tersebut bereaksi dengan oksigen dan menyebabkan korosi. Korosi ini akan mengurangi area efektif baja dan dapat meningkatkan intensitas tegangan pada takik retaknya. Korosi pada plat buhul seiring dengan bertambahnya muatan kendaraan yang melintasi jembatan dapat menyebabkan jembatan runtuh [4], [5]. Di sisi lain, kegagalan daktail yang diikuti oleh deformasi plastis yang berlebihan dapat diprediksi dengan baik menggunakan analisis elemen hingga nonlinier. Jika pemeliharaan elemen jembatan tidak dilakukan dengan benar dapat menyebabkan kerusakan yang lebih cepat dan menyebabkan kegagalan seluruh jembatan [6]. 
Studi ini menyajikan analisa statis nonlinier untuk mempelajari perilaku struktur jembatan busur rangka baja jenis $a$ half through arch. Tujuannya adalah untuk mengevaluasi elemen rangka jembatan yang diharapkan terjadi tegangan leleh di kedua ujung elemen akibat respons gaya aksial (gaya tekan atau tarik) atau diharapkan terjadi tegangan leleh di tengah elemen akibat gaya aksial tekan yang melebihi beban tekuk. Tahapan pemberian beban dorong adalah pemberian beban nonlinier gravitasi (berat sendiri, beban tambahan dan beban hidup kendaraan UDL) yang diaplikasikan terlebih dahulu kemudian diberikan beban dorong seismik arah horisontal pada deck jembatan. Setelah beban dorong diberikan pada struktur maka perlu dilakukan pengujian terhadap respons struktur jembatan. Dalam analisa, kekuatan sambungan chord (plat gusset dan baut) didesain lebih kuat daripada elemen rangka. Sehingga, kegagalan dikontrol oleh deformasi plastik yang berlebihan dan/atau tekuk elemen rangka.

\section{Pemodelan Jembatan}

Jembatan busur rangka baja dengan jenis a-half through arch bridge yang dimodelkan adalah jembatan bentang sederhana dengan panjang bentang total sekitar $100 \mathrm{~m}$ dan tinggi 21,42 m. Jembatan dibagi menjadi 20 divisi dengan panjang masing-masing divisi adalah $5 \mathrm{~m}$ dan ketinggian elemen rangka vertikal adalah 3,42 $\mathrm{m}$. Gambar 1 menunjukkan detail dari pemodelan jembatan busur rangka baja jenis a-half through arch. Gambar 1(a) dan Gambar 1(b) menunjukkan tampak atas dan bawah jembatan busur. Ikatan angin busur atas dan bawah mengikuti bentuk huruf K. Gambar 1(c) menunjukkan tampak samping jembatan busur rangka baja. Pada Gambar 1(c) diberikan penomoran (As) pada titik bagian atas busur yang akan digunakan untuk diskusi selanjutnya. Jembatan ini dirancang agar sesuai dengan dua jalur kendaraan dengan lebar bentang jalur 3,5 m. Lebar total jembatan yang diukur dari pusat ke pusat lengkungan rangka luar adalah $9 \mathrm{~m}$. Ketinggian maksimum jembatan diukur dari bagian atas dek jembatan ke busur rangka baja terendah di rentang tengah adalah 14,58 m. Dek jembatan dirancang menggunakan pelat beton bertulang dengan ketebalan desain 200 $\mathrm{mm}$.

Material untuk elemen busur rangka baja memiliki fy 290 MPa dan fu $500 \mathrm{MPa}$ (BJ 50). Untuk elemen baja sekunder seperti gelagar melintang dan gelagar memanjang, fy 250
MPa dan fu $410 \mathrm{MPa}$ (BJ 41). Untuk batang penggantung (hanger), material yang digunakan memiliki tegangan leleh minimum $510 \mathrm{MPa}$ dan tegangan putus minimum $690 \mathrm{MPa}$. Batang penggantung dirancang memiliki diameter $72 \mathrm{~mm}$ (Thread M76). Dengan menggunakan diameter batang penggantung tersebut memiliki beban leleh dan beban putus minimum berturut-turut $1,986 \mathrm{kN}$ dan $2,635 \mathrm{kN}$.

Dalam desain struktur jembatan, pemodelan pembebanan menggunakan peraturan pembebanan jembatan [7]. Beban gempa yang direncanakan menggunakan respon spectrum untuk wilayah kota Surabaya sesuai dengan peraturan jembatan terhadap beban gempa [8]. Spesifikasi site class tanah adalah E. Nilai untuk $\mathrm{S}_{\mathrm{S}}, \mathrm{S}_{1}$, PGA dan $\mathrm{A}_{\mathrm{S}}$ masingmasing adalah $0,490 \mathrm{~g}, 0,229 \mathrm{~g}, 0,248 \mathrm{~g}$ dan 0,362 g. Nilai untuk $\mathrm{S}_{\mathrm{DS}}$ dan $\mathrm{S}_{\mathrm{D} 1}$ masing-masing adalah 0,849 $\mathrm{g}$ dan 0,707 g. Saat mendesain bagian rangka baja, ada tiga kondisi batas yang dipertimbangkan yaitu kondisi batas kekuatan ultimate, kondisi batas kejadian ekstrim, dan kondisi batas layan.

Sebelum dilakukan analisa pushover, struktur jembatan harus direncanakan terlebih dahulu. Hasil analisa struktur jembatan busur rangka baja yang direncanakan adalah sebagai berikut $(\mathrm{WF}=$ Flange Lebar, $\mathrm{B}=$ Profil Kotak Berongga):

- Balok silang - WF 900x300x16x28

- Stringer - WF 390x300x10x16

- Gelagar utama lantai - B 500x500x25×25

- Busur vertikal - B 180x180x6.3x6.3

- Busur diagonal - B 220x220x8x8

- Elemen longitudinal busur atas - B 350x350x19x19, B $400 \times 400 \times 25 \times 25, \mathrm{~B} 500 \times 500 \times 25 \times 25$, B 600x600x25x25, B $800 \times 600 \times 45 \times 45$

- Elemen longitudinal busur bawah - B 350x350x19x19, B $400 \times 400 \times 25 \times 25$, B 500x $500 \times 25 \times 25$

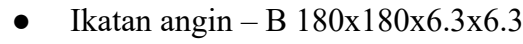

- Lateral brace - B 220x220x8x8

- Portal akhir - B 800x600x45x45

Gambar 2 menunjukkan model gambar rangka 3D dari jembatan busur rangka baja sederhana (bentang tunggal) dengan jenis jembatan a-half through arch.

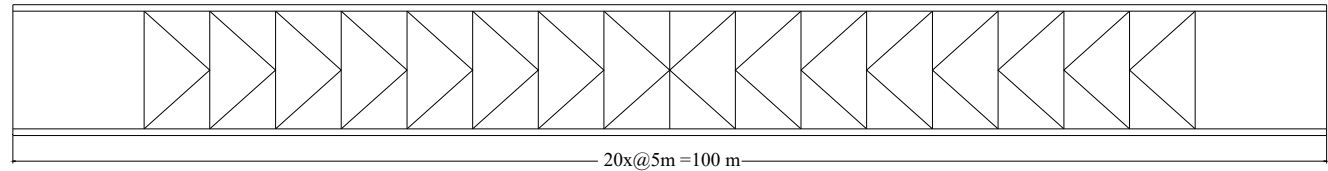

(a) Tampak Atas Rangka Busur 


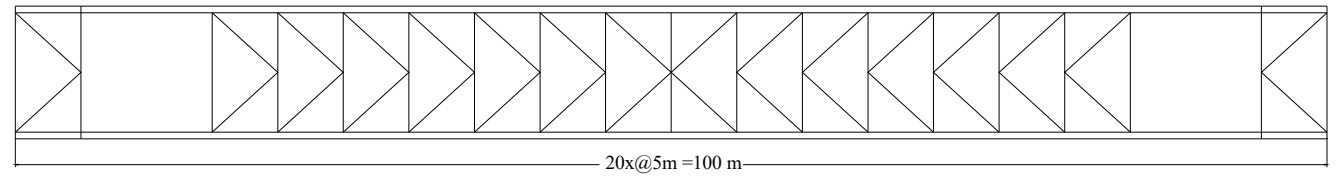

(b) Tampak Bawah Rangka Busur

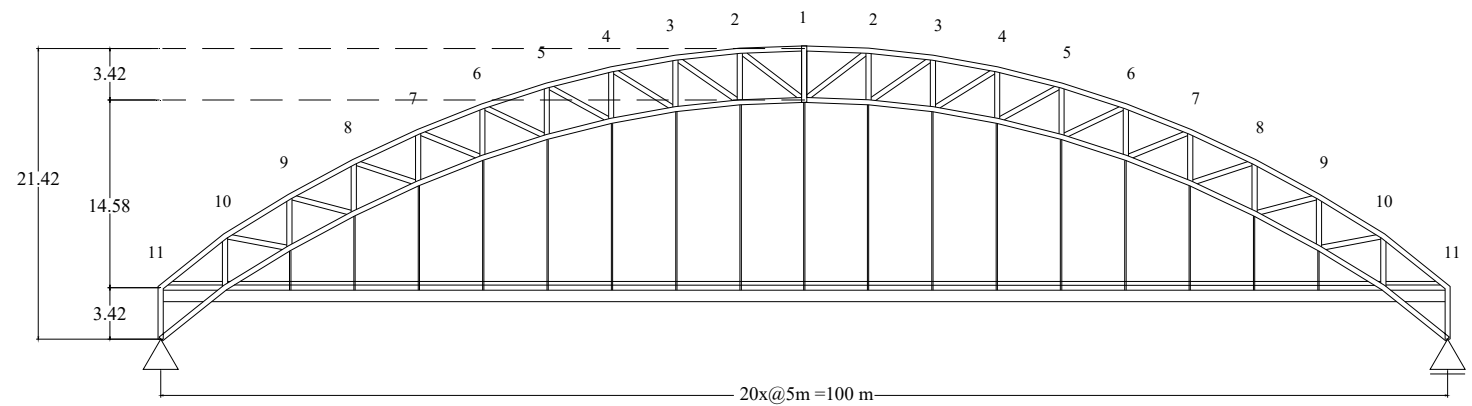

(c) Tampak Longitudinal

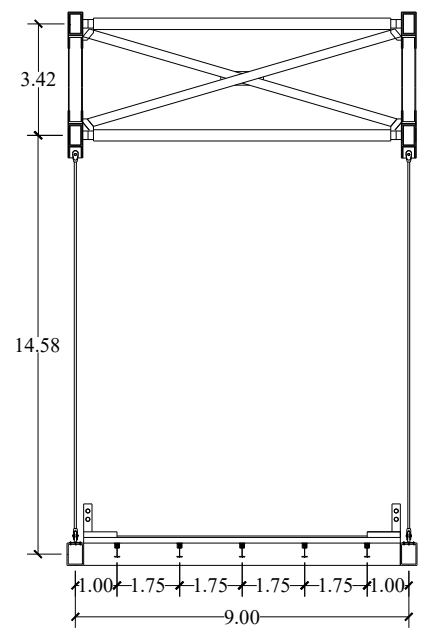

(d) Potongan Melintang Tengah Bentang

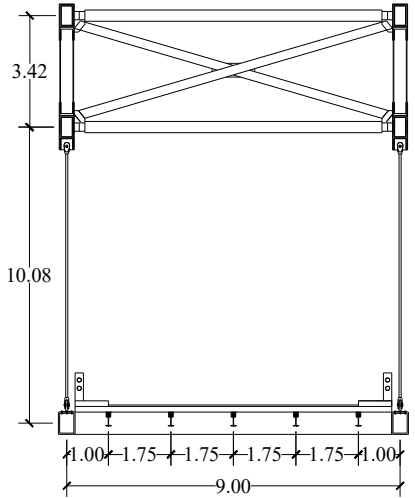

(e) Potongan Melintang As 6

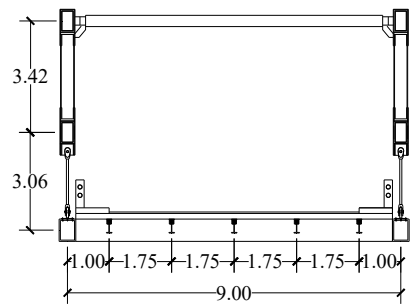

(f) Potongan Melintang As 9

Gambar 1. Tampak Umum Jembatan Busur Rangka Baja 


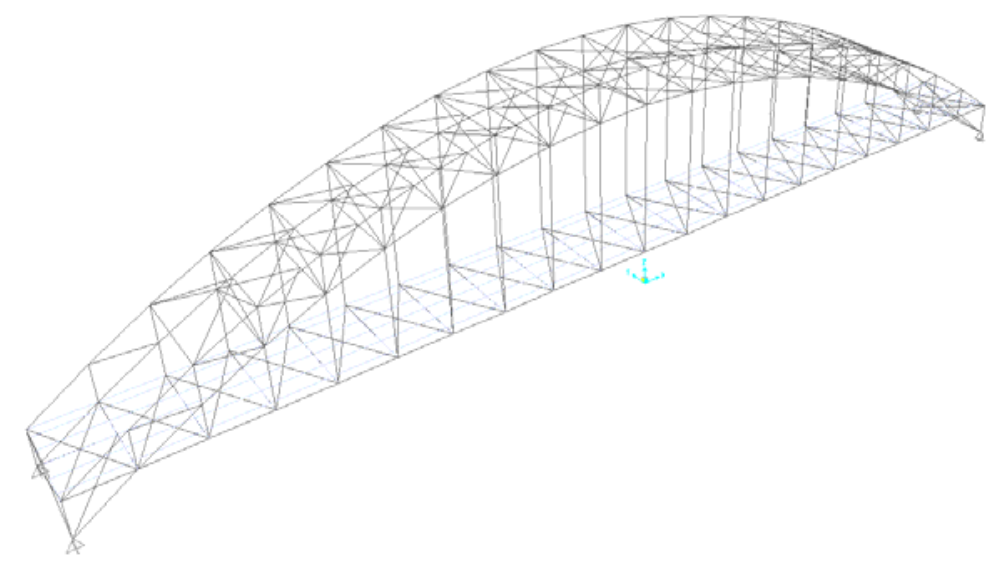

Gambar 2. Pemodelan Rangka 3D Jembatan a-Half Through Arch

\section{Metode}

Analisa pushover dilakukan dengan menggunakan paket software SAP 2000. Analisis statis nonlinier ini sering digunakan untuk mengevaluasi perilaku nonlinier struktur bangunan bertingkat tinggi. Ketika mengevaluasi bangunan bertingkat tinggi, gaya lateral yang bervariasi di seluruh ketinggian struktur meningkat secara monotonik hingga target perpindahan yang telah ditentukan tercapai atau strukturnya runtuh. Gaya lateral versus perpindahan atap dapat diplot berdasarkan hasil analisis dan disebut sebagai kurva kapasitas [9]. Setelah kurva kapasitas diperoleh, kinerja struktur dapat dievaluasi melalui format Acceleration Displacement Response Spectrum (ADRS), yang diperoleh dari mengubah kurva kapasitas dan kurva respons spektrum (demand) menjadi bentuk percepatan spectral-perpindahan spektral $\left(\mathrm{S}_{\mathrm{A}}-\right.$ $\left.\mathrm{S}_{\mathrm{D}}\right)[10]$.

Dalam melakukan analisa statis nonlinier pada struktur jembatan, metode yang tepat untuk menetapkan beban seismik lateral pada dek jembatan harus dipertimbangkan dengan hati-hati. Dalam studi ini, dek jembatan diasumsikan cukup kuat sehingga dek jembatan direncanakan sebagai diafragma (rigid). Beban seismik lateral dihitung dengan menggunakan faktor reduksi beban seismik (R) yang diaplikasikan pada pusat diafragma jembatan dengan eksentrisitas nol di kedua arah $\mathrm{x}$ dan y (tengah bentang). Material propertis elemen rangka ditetapkan untuk menerima beban aksial tekan dan tarik dengan harapan terjadi leleh di kedua ujungnya. Penetapan sendi ini dapat menggunakan "Auto P" di SAP 2000. Kemudian di tengah elemen rangka ditetapkan tambahan sendi akibat beban aksial tekan pada setiap elemen rangka. Jenis sendi ini ditentukan melalui "user defined" pada SAP 2000 dengan harapan sendi plastis terjadi pada tengah elemen. Kapasitas buckle (tekuk) dari elemen rangka dihitung menggunakan rumus Euler tekuk elastik mode pertama. Untuk beban tarik dalam perilaku sendi tekuk, diharapkan terjadi perilaku regangan elastis yang besar sehingga kegagalan elemen rangka terjadi di kedua ujung elemen akibat beban tarik tersebut.

\section{Hasil Analisa dan Pembahasan}

Gambar 3 menunjukkan reaksi geser dasar (base shear) sebagai fungsi dari perpindahan lateral dek jembatan. Reaksi geser dasar maksimum adalah 2480.8 ton. Setelah geser dasar maksimum tercapai, kapasitas geser dasar jembatan turun secara signifikan. Penurunan signifikan pada geser dasar ini disebabkan oleh kegagalan tiba-tiba pada elemen utama rangka busur yang diakibatkan oleh tegangan tekan pada elemen yang kritis (Gambar 5). Identifikasi kinerja struktur terhadap jumlah kegagalan rangka ditunjukkan pada Tabel 1. Terlihat dari Tabel 1 bahwa ada empat sendi plastis elemen yang mengalami collapse secara tiba-tiba pada step 3 .

Untuk menghubungkan antara level kinerja dengan respons spektrum pada kota Surabaya, kurva ADRS dievaluasi dan ditunjukkan pada Gambar 4. Dalam analisa pushover, salah satu tujuan penting adalah mengevaluasi titik kinerja (performance point) struktur. Titik kinerja ini dievaluasi pada titik di mana kurva demand dan kurva kapasitas saling berpotongan. Dari Gambar 4, gaya geser dasar diperoleh ketika perpindahan mencapai $37 \mathrm{~mm}$ adalah 1001.4 ton. Nilai percepatan spektral dan perpindahan spektral pada titik kinerja masing-masing adalah $0,905 \mathrm{~g}$ dan $28 \mathrm{~mm}$. 


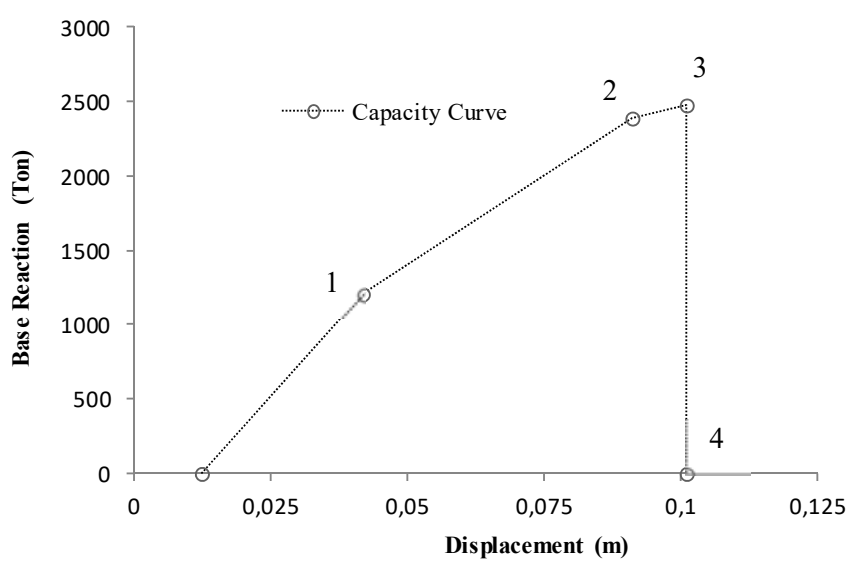

Gambar 3. Geser dasar versus kurva perpindahan

Tabel 1. Evaluasi Kinerja Elemen Struktur

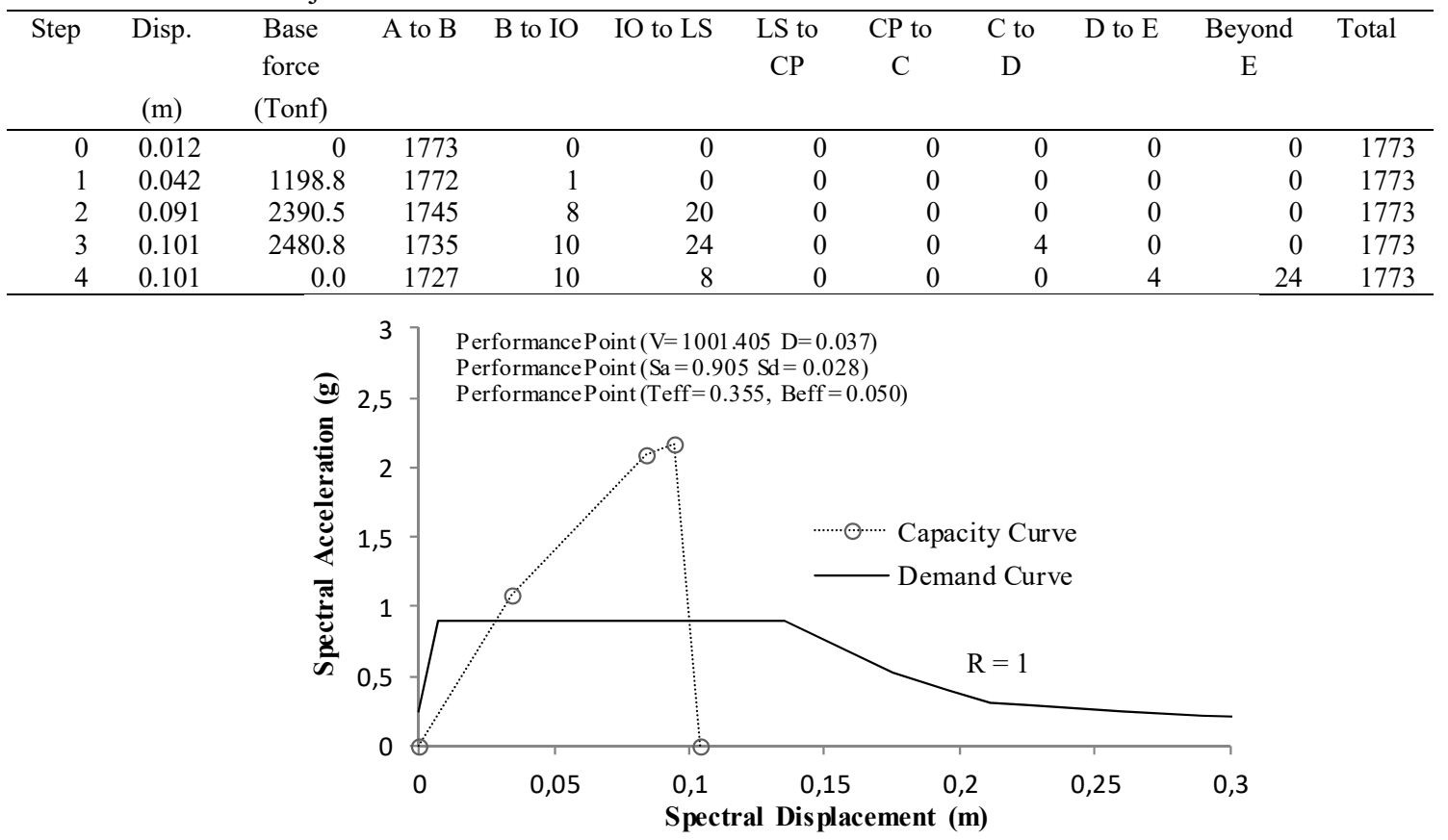

Gambar 4. ADR (ATC 40 Kapasitas Spectrum)

- Formasi Sendi Plastis

Dengan menggunakan Gambar 4 bahwa titik kinerja tercapai pada Teff $=0,355$ detik dan menggunakan Tabel 2 menunjukkan bahwa tingkat kinerja dengan Teff tersebut tercapai pada langkah 1 dan dari Tabel 1, dapat ditentukan bahwa tingkat kinerja adalah Immediate Occupancy (IO).

Tabel 2. Kurva Demand dan Kapasitas - ATC40

\begin{tabular}{|c|c|c|c|c|c|c|c|c|}
\hline Step & $\begin{array}{c}\text { Teff } \\
\text { Second }\end{array}$ & Beff & $\begin{array}{c}\text { Sd Capacity } \\
\text { M }\end{array}$ & Sa Capacity & $\begin{array}{l}\text { Sd Demand } \\
\text { M }\end{array}$ & Sa Demand & Alpha & PFPhi \\
\hline 0 & 0.3553 & 0.05 & 0 & 0 & 0.0284 & 0.905 & 1 & 1 \\
\hline 1 & 0.3553 & 0.05 & 0.0340 & 1.0834 & 0.0284 & 0.905 & 0.9397 & 0.8680 \\
\hline 2 & 0.4027 & 0.0991 & 0.0841 & 2.0881 & 0.0284 & 0.7045 & 0.9722 & 0.9341 \\
\hline 3 & 0.4196 & 0.1244 & 0.0948 & 2.1671 & 0.0279 & 0.6385 & 0.9721 & 0.9338 \\
\hline 4 & 0.0000 & 0.05 & 0.1039 & 0 & 0.0279 & 0.6385 & 0.9232 & 0.8516 \\
\hline
\end{tabular}


pada Gambar 5 (a) menunjukkan bahwa sendi plastis pertama diperoleh pada elemen vertikal rangka busur pada As 9 dekat Portal akhir. Pada Gambar 5 (b) menunjukkan bahwa elemen longitudinal busur atas yang terletak antara As 7 dan
As 8 mencapai kapasitas puncak yang menyebabkan struktur hampir terjadi collapse pada step 3. Gambar 5(c) menunjukkan bahwa terjadi keruntuhan secara tiba-tiba hingga kapasitas struktur turun secara signifikan.

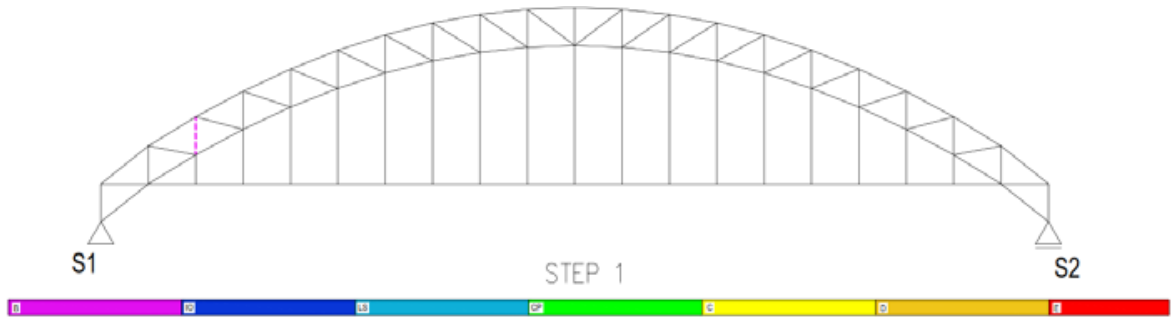

(a)

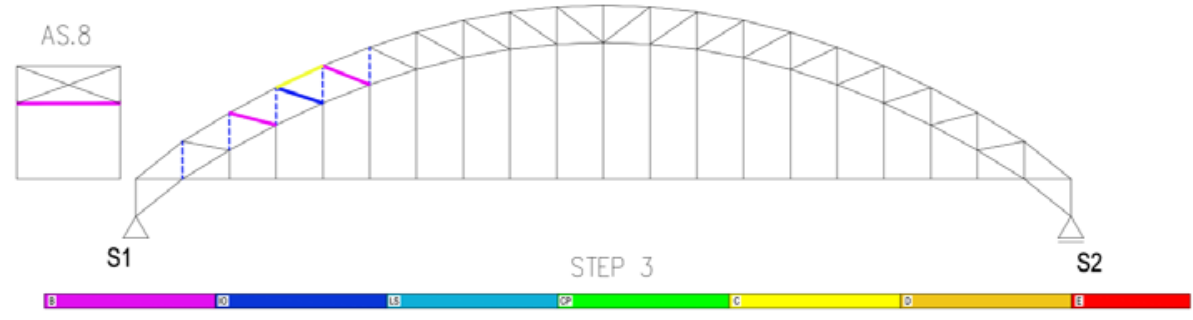

(b)

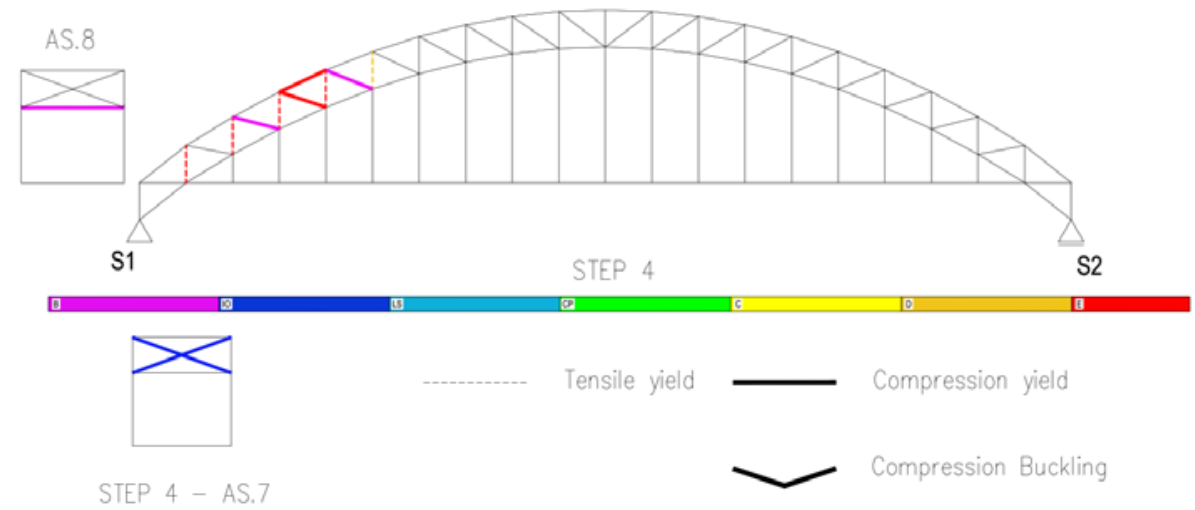

(c)

Gambar 5. Formasi Sendi Plastis; (a) Pembentukan sendi plastis pertama pada step 1;

(b) Struktur mencapai kapasitas puncak pada step 3; (c) Struktur collapse pada step 4

- Evaluasi Daktilitas

Berdasarkan Gambar 5 (a), Gambar 3 dan Tabel 1, dapat ditentukan nilai perpindahan pada leleh pertama $(\delta y)$ yaitu pada step 1 sebesar 0,042 m. Dari Gambar 3 dan Tabel 1 menunjukkan bahwa nilai perpindahan maksimum $(\delta \mathrm{u})$ terjadi pada step 3 adalah $0,101 \mathrm{~m}$. Berikut nilai daktilitas $(\mu)$ berdasarkan analisa pushover sebagai berikut.

$$
\begin{aligned}
\mu \quad & =\delta \mathrm{u}: \delta \mathrm{y} \\
& =0.101 \mathrm{~m}: 0.042 \mathrm{~m} \\
& =2.4
\end{aligned}
$$

\section{Kesimpulan}

Studi ini menyajikan analisa pushover nonlinier statis dari jembatan busur dengan bentuk a-half through arch bridge 
dengan bentang $100 \mathrm{~m}$. Struktur jembatan tersebut didesain terhadap zona gempa kota Surabaya sesuai dengan SNI 28332016. Dalam studi ini kurva kapasitas dan kurva demand berpotongan pada zona immediate occupancy (IO) dan level kinerja yang tercapai pada tahapan beban pertama (step-1). Untuk beban kearah longitudinal, transformasi sendi plastis pertama dimulai pada elemen busur vertikal As 9 yang terletak dekat dengan portal akhir. Pada tahapan pembebanan ketiga (step 3), elemen longitudinal busur pada bagian rangka atas yang terletak antara As 7 dan As 8 mencapai kapasitas puncaknya dan menyebabkan sistem struktur hampir mengalami kegagalan (collapses). Pada tahapan pembebanan terakhir (step 4) ada beberapa elemen struktur rangka yang mengalami kerusakan diantaranya adalah elemen struktur rangka diagonal antara As 7 dan As 8 serta elemen rangka vertikal yang terletak pada As 6 sampai dengan As 10. Dari studi ini, dapat diketahui elemen-elemen struktur mana saja yang akan dan dapat mengalami kerusakan sehingga dapat diambil beberapa penanganan khusus pada saat perancangan.

\section{Daftar Pustaka}

[1] PU, "Investigasi Jembatan Rangka Baja," Jakarta, 2009.

[2] The Jakarta Post, "Central Sulawesi Quake: What We Know so Far," Jakarta, 28-Sep-2018.

[3] Tempo, "Tangani Jembatan Widang Ambruk, Menteri PU Kirim Kerangka Baja," Tuban, 17-Apr2018.

[4] Abolhassan Astaneh-Asl, "Progressive Collapse of Steel Truss Bridges, The Case of I-35W Collapse," in Seventh International Conference on Steel Bridge, 2008.

[5] Kazuhiro Miyachi, S. Nakamura, and A. Manda, "Progressive Collapse Analysis of Steel Truss Bridges and Evaluation of Ductility," J. Constr. Steel Res., pp. 192-200, 2012.

[6] E. Yamaguchi, R. Okamoto, and K. Yamada, "PostMember-Failure Analysis Method of Steel Truss Bridge," Procedia Eng., pp. 656-661, 2011.

[7] SNI:1725, Pembebanan untuk Jembatan. Jakarta: Standar Nasional Indonesia, 2016.

[8] SNI:2833, Perencanaan Jembatan terhadap Beban Gempa. Jakarta: Standar Nasional Indonesia, 2016.

[9] PEER-Center, Guidelines for Nonlinear Analysis of Bridge Strcutures in California. University of California Berkeley: 9. Pacific Earthquake Engineering Research Center, 2008.

[10] ATC-40, Seismic Evaluation and Retrofit of Concrete Building. Redwood City, California, U.S.A.: Applied Technology Council, 1996. 
